\title{
Qualidade fisiológica das sementes de pinhão manso (Jatropha curcas L.) durante o armazenamento em três ambientes
}

\section{Physiological quality of jatropha seeds (Jatropha curcas L.) during storage in three environments}

\author{
Tarcísio Honório Chaves ${ }^{1}$; Osvaldo Resende ${ }^{2 *}$; \\ Valdiney Cambuy Siqueira ${ }^{3}$, Renan Ullmann ${ }^{4}$
}

\section{Resumo}

Objetivou-se avaliar a qualidade fisiológica das sementes de pinhão manso durante o armazenamento em diferentes condições. O experimento foi desenvolvido nos Laboratórios de Pós-colheita de Produtos Vegetais e de Sementes do Instituto Federal de Educação, Ciência e Tecnologia Goiano - Campus Rio Verde-GO. Foram utilizadas sementes de pinhão manso com teor de água de $6,80 \%$ (b.u.), aproximadamente. As sementes foram armazenadas em condição de ambiente natural, câmara refrigerada e climatizada por um período de um ano. Foram realizadas avaliações de teor de água, absorção de água, condutividade elétrica, porcentagem de germinação e índice de velocidade de germinação aos $0,2,4,6,8,10$ e 12 meses de armazenamento. As condições de temperatura e umidade relativa do ar comprometeram a estrutura das sementes de pinhão manso ao longo do tempo, principalmente em ambiente natural. $\mathrm{O}$ armazenamento em ambientes refrigerados e climatizados reduzem com menor intensidade a qualidade fisiológica das sementes.

Palavras-chave: Jatropha curcas L., teor de água, vigor, germinação, conservação

\begin{abstract}
This work was carried out to evaluate the quality of jatropha seeds during storage at three temperatures and humidity. The experiment was conducted in Pós-colheita de Produtos Vegetais e de Sementes laboratories of Instituto Federal de Educação, Ciência e Tecnologia Goiano - Campus Rio Verde-GO. Jatropha seeds with moisture content at $6.80 \%$ (w.b.), approximately. The seeds were stored in natural environments conditions, refrigerated and climatic conditions for one year, evaluating the moisture content, water absorption, electrical conductivity, germination and germination speed index in $0,2,4$, $6,8,10$ and 12 months of storage. Concluded that the conditions of temperature and relative humidity committed the structure of the seeds of jatropha over time, mainly in natural conditions air, and than storage in refrigerated and climatic conditions reduce to a lesser extent the seed quality.
\end{abstract}

Key words: Jatropha curcas L., moisture content, vigor, quality, seed

1 Discente em Agronomia, Instituto Federal de Educação, Ciência e Tecnologia Goiano, IF Goiano, Campus Rio Verde. Bolsista PIBIC/CNPq. E-mail: tarcisio.chaves@hotmail.com

2 Eng ${ }^{\circ}$. Agrícola, Prof. Dr. do IF Goiano, Campus Rio Verde. E-mail: osvresende@yahoo.com.br

3 Doutorando em Engenharia Agrícola, Universidade Federal de Lavras, UFLA, Lavras, MG. E-mail: vcambuy@yahoo.com

4 Discente em Agronomia do IF Goiano, Campus Rio Verde. Bolsista PIBIC/CNPq. E-mail: renanullmann@hotmail.com Autor para correspondência 


\section{Introdução}

A crescente preocupação mundial com o meio ambiente, juntamente com a busca por fontes de energia renováveis, coloca o biodiesel no centro das atenções e interesses. Diversos países, dentre eles o Brasil, procuram o caminho do domínio tecnológico desse biocombustível, tanto em nível agronômico como industrial, o que deverá provocar fortes impactos na economia brasileira e na política de inclusão social do país (ABDALLA et al., 2008).

Existe grande diversidade de plantas oleaginosas aptas a serem utilizadas na produção do biodiesel, dentre elas destaca-se o pinhão manso (Jatropha curcas L.). Souza et al. (2009), observaram uma concentração média de 40,33 $\pm 1,91 \%$ de lipídeos na matéria seca de sementes de pinhão manso. Outros atributos estão relacionados ao óleo, pois não é comestível e, portanto, não seria utilizado para a alimentação humana (SATURNINO et al., 2005). Santos et al. (2009), destacam que a distribuição geográfica do pinhão manso é bastante vasta devido à sua rusticidade, resistência a longas estiagens, à pragas e doenças, sendo adaptável a condições edafoclimáticas muito variáveis, além da produção de óleo com todas as qualidades necessárias para ser transformado em biodiesel.

A armazenagem dos produtos agrícolas é uma excelente alternativa para atender à logística de produção e comercialização de alimentos. Tendo em vista que a produção de pinhão manso não ocorre durante todo o ano, o armazenamento é uma etapa pós-colheita de fundamental importância para garantir a oferta do produto no período de entressafra. Segundo Abdul-Baki e Anderson (1972), as condições do ambiente de armazenagem influenciam diretamente a qualidade e a viabilidade das sementes, logo que a deterioração das sementes pode ser considerada como toda e qualquer transformação degenerativa irreversível, após terem atingido nível máximo da qualidade fisiológica.

Segundo Silva (2008), o teor de água das sementes, a temperatura e a umidade relativa do ar são consideradas cruciais à interação de fatores bióticos e abióticos que promovem a deterioração das sementes. O mesmo pesquisador afirma que, há um aumento da intensidade respiratória das sementes, que é proporcional ao aumento da temperatura, e dependência do teor de água das mesmas.

Os produtos agrícolas possuem a propriedade de realizar trocas de água sob a forma de vapor, com o ambiente que os envolve. Essas trocas acontecem com o ganho ou a perda de água, fenômenos conhecidos, respectivamente, por adsorção e dessorção, de acordo com as características higroscópicas recíprocas do produto e do ar. A afinidade existente entre a água e os outros componentes (gordura, amido, açúcar, proteínas etc.) de um produto, define sua higroscopicidade (BROOKER; BAKKER-ARKEMA; HALL, 1992).

As trocas de água entre as sementes e o ar podem promover danos nas estruturas das sementes e, esses danos promovem a lixiviação de exsudatos, ou seja, a perda de componentes químicos. Segundo Vieira et al. (2002), pode-se destacar o teste de condutividade elétrica, no qual a qualidade das sementes é avaliada indiretamente por meio da determinação da quantidade de lixiviados na solução de embebição das sementes. Desta forma, o teste de condutividade elétrica, além do potencial de avaliação fisiológica das sementes, também vem sendo utilizado por diversos autores como índice de avaliação da qualidade tecnológica de grãos devido à danificação mecânica (ANDRADE et al., 1999; AFONSO JÚNIOR; CORRÊA; ANDRADE 2003; GONELI et al., 2007).

A absorção de água das sementes está em função da diferença entre o teor de água de saturação e o teor de água em um determinado tempo, chamada força motriz (RESIO; AGUERRE; SUAREZ, 2005). No entanto a quantidade de água absorvida depende da espécie, semente, variedade ou cultivar, composição química da semente, teor de água inicial, natureza do tegumento, quantidade de água 
disponível (BEWLEY; BLACK, 1994), bem como da temperatura e do tempo de armazenamento (RESENDE et al., 2008).

Considerando as vantagens da produção de biodiesel, a importância do armazenamento, bem como o reflexo dessa etapa pós-colheita na qualidade dos produtos agrícolas, realizou-se o presente trabalho com o objetivo de avaliar a qualidade fisiológica das sementes de pinhão manso durante o armazenamento em três condições de temperatura e umidade relativa.

\section{Material e Métodos}

O experimento foi desenvolvido nos Laboratórios de Pós-colheita de Produtos Vegetais e de Sementes do Instituto Federal de Educação, Ciência e Tecnologia Goiano - Campus Rio Verde, município de Rio Verde-GO, a $17^{\circ} 47^{\prime} 53^{\prime \prime}$ de latitude (S) e $51^{\circ} 55^{\prime} 53^{\prime}$ ' de longitude (W). A colheita dos frutos do pinhão manso e a trilhagem das sementes foram realizadas manualmente, obtendo sementes com teor de água de $30 \%$ (b.u.).

Para a condução do experimento as sementes ficaram expostas ao ambiente natural para reduzir o seu teor de água até 6,80\% (b.u.), determinado pelo método de secagem em estufa, a $105 \pm 1{ }^{\circ} \mathrm{C}$, durante 24 horas, em três repetições (BRASIL, 2009). Utilizaram-se $500 \mathrm{~g}$ de sementes acondicionadas em sacos de papel com capacidade de 1,0 kg e armazenadas por um ano em três condições distintas: condição de ambiente natural $\left(26 \pm 3{ }^{\circ} \mathrm{C}\right.$; $55 \pm 12 \%$ UR), câmara climatizada $\left(18 \pm 1{ }^{\circ} \mathrm{C} ; 53 \pm 7\right.$ $\%$ UR) e refrigerada $\left(5 \pm 1{ }^{\circ} \mathrm{C} ; 79 \pm 5 \%\right.$ UR). Durante o armazenamento a umidade relativa (UR) e a temperatura foram registradas por um data logger digital (precisão: $0,1{ }^{\circ} \mathrm{C} ; 5,0 \% \mathrm{UR}$ ).

As sementes foram submetidas às avaliações de absorção de água, teor de água, condutividade elétrica, porcentagem de germinação e índice de velocidade de germinação aos $0,2,4,6,8,10$ e 12 meses de armazenamento.
Para o teste de absorção de água as amostras foram submetidas à embebição em água destilada e mantidas em câmara B.O.D. $\left(25,0 \pm 1,0{ }^{\circ} \mathrm{C}\right)$ por um período de $12 \mathrm{~h}$. Utilizou-se um recipiente plástico (capacidade de $200 \mathrm{~mL}$ ) contendo $80 \mathrm{~mL}$ de água destilada juntamente com $20 \mathrm{~g}$ de sementes, perfazendo uma relação em massa de 4: 1 de acordo com a metodologia descrita por Abu-Ghnnam e Mckenna (1997). Depois do período de hidratação, as amostras foram retiradas dos recipientes e colocadas em papel de filtro para escorrimento da água superficial durante dois minutos. O teor de água depois da absorção foi obtido por meio da seguinte equação:

$$
\mathrm{U}^{*}=\frac{\mathrm{M}_{\mathrm{e}}-\mathrm{M}_{\mathrm{s}}}{\mathrm{M}_{\mathrm{s}}}
$$

em que,

$\mathrm{U}^{*}$ : teor de água do produto, (decimal b.s.);

$\mathrm{M}_{\mathrm{e}}$ : massa depois da embebição, $\mathrm{kg}$;

$\mathrm{M}_{\mathrm{s}}$ : massa da matéria seca do produto em $\mathrm{kg}$.

O teste de condutividade elétrica (CE) foi realizado segundo metodologia descrita por Vieira e Krzyzanowski (1999). Foram contadas e pesadas quatro subamostras de 20 sementes, para cada tratamento. As amostras foram colocadas em copos de plástico com $75 \mathrm{~mL}$ de água deionizada e mantida em uma câmara com temperatura controlada a 25,0 $\pm 1{ }^{\circ} \mathrm{C}$, durante 24 horas. Depois desse período, efetuou-se leitura da condutividade elétrica por meio de condutivímetro portátil, com leitura expressa em $\mu \mathrm{S} . \mathrm{cm}^{-1} \cdot \mathrm{g}^{-1}$.

O teste de germinação foi conduzido com quatro subamostras de 25 sementes de cada lote, em rolos de papel toalha tipo "Germitest", em germinador tipo "Mangelsdorf” regulado para manter a temperatura constante de $25 \pm 1{ }^{\circ} \mathrm{C}$. A quantidade de água adicionada foi equivalente a 2,5 vezes a massa do substrato seco, visando o umedecimento adequado e, consequentemente, a uniformização do teste. As 
interpretações foram efetuadas a partir do $2^{\circ}$ dia após a semeadura, segundo os critérios estabelecidos nas Regras para Análise de Sementes (BRASIL, 2009). Posteriormente computou-se a porcentagem média de germinação e o índice de velocidade de germinação (IVG $=n_{1} \cdot d_{1}{ }^{-1}+n_{2} \cdot d_{2}{ }^{-1}+n_{3} \cdot d_{3}{ }^{-1} \ldots n \cdot d_{n}$ ${ }^{-1}$; sendo $\mathrm{n}_{1}=$ sementes germinadas no primeiro dia da contagem; $\mathrm{n}_{2}=$ sementes germinadas no segundo dia da contagem; $\mathrm{n}_{3}=$ sementes germinadas no terceiro dia da contagem; $n_{n}=$ sementes germinadas no enésimo dia da contagem; $d_{1}=$ primeiro dia, $d_{2}=$ segundo dia; $d_{3}=$ terceiro dia, $d_{n}=$ enésimo dia), conforme Nakagawa (1994).

$\mathrm{O}$ experimento foi montado em delineamento inteiramente casualizado, segundo esquema de parcela subdividida, sendo três condições de armazenamento (ambiente natural, câmara refrigerada e câmara climatizada) nas parcelas e os meses de avaliação nas subparcelas. As médias foram comparadas pelo teste de Tukey a 5\% de significância.

\section{Resultados e Discussão}

Nas Figuras 1 e 2 estão apresentados os valores médios mensais da temperatura e da umidade relativa do ar nos três ambientes de armazenamento das sementes de pinhão manso. Nota-se que a câmara refrigerada promoveu maior umidade relativa, decorrente da baixa temperatura deste ambiente, apresentando menores oscilações ao longo do tempo. Já o ambiente natural de armazenamento apresentou maiores alterações nas condições do ar, em virtude das mudanças climáticas decorrentes das estações do ano. Verifica-se, ainda, que o ambiente climatizado apresentou menores valores de umidade relativa devido ao sistema de resfriamento retirar vapor d'água desta câmara.

Na Tabela 1 está apresentado o resumo da análise de variância para as variáveis analisadas. Verificase que os ambientes e o tempo de armazenamento influenciaram nas análises do teor de água, porcentagem de germinação e IVG. Para a absorção de água não houve interação entre os fatores e para a condutividade elétrica não foi identificado efeito do ambiente de armazenamento.

Figura 1. Umidade relativa média nos ambientes de armazenamento das sementes de pinhão manso durante 12 meses.

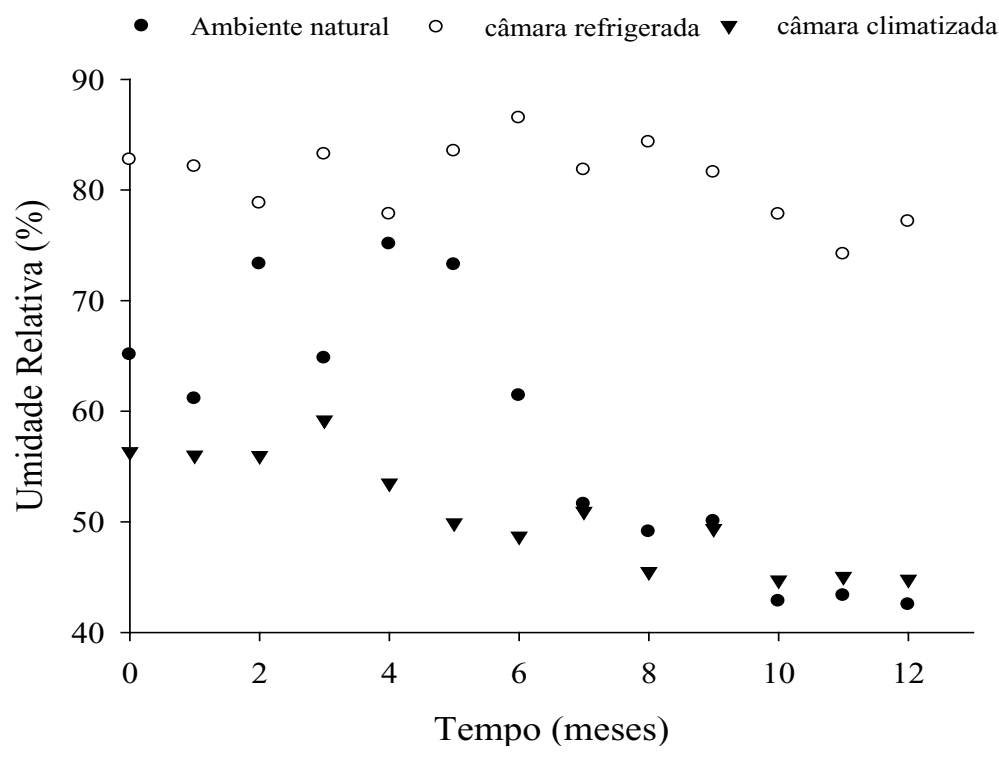

Fonte: Elaboração dos autores. 
Figura 2. Temperatura média ao longo do armazenamento das sementes de pinhão manso em três condições distintas.

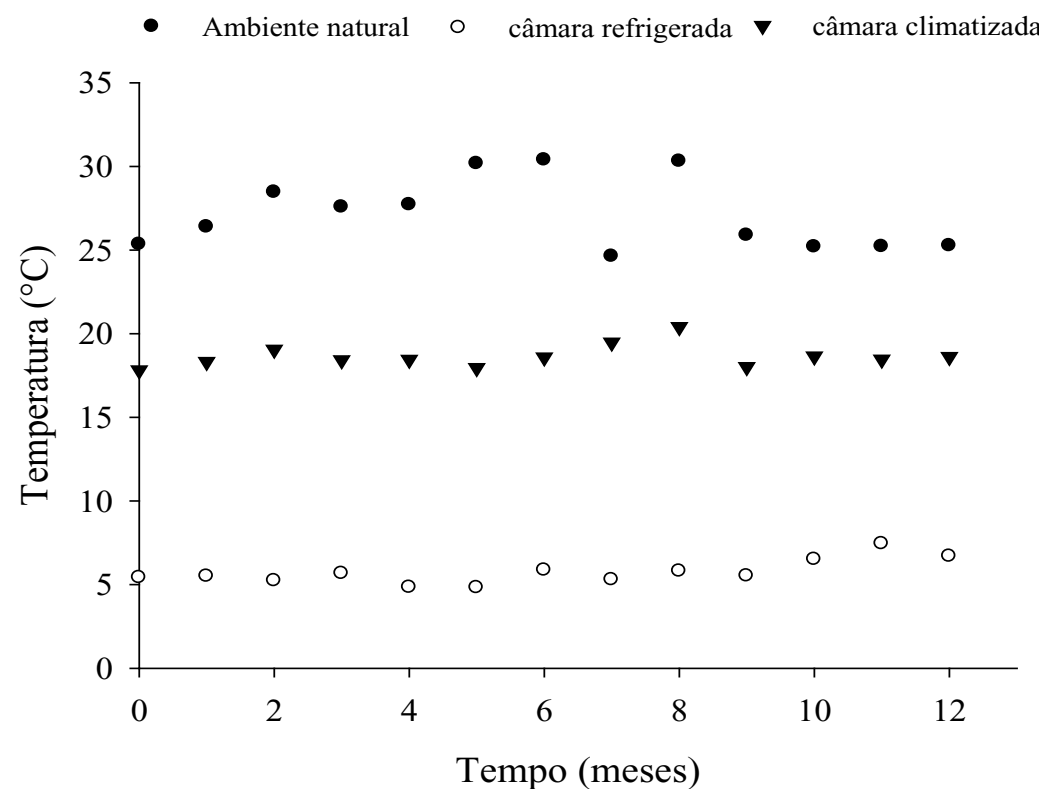

Fonte: Elaboração dos autores.

Tabela 1. Resumo da análise de variância para teor e absorção de água, condutividade elétrica, porcentagem de germinação e índice de velocidade de germinação (IVG), durante o armazenamento das sementes de pinhão manso em diferentes ambientes por 12 meses.

\begin{tabular}{lccc}
\hline Variáveis analisadas & Fonte(s) de variação & Quadrados médios & CV (\%) \\
\hline \multirow{2}{*}{ Teor de água } & Ambiente & $5,676554^{*}$ & 11,44 \\
& Meses & $0,606174^{* *}$ & 4,70 \\
& Ambiente x Meses & $0,734313^{* *}$ & 2,43 \\
\multirow{2}{*}{ Absorção de água } & Ambiente & $0,001944^{*}$ & 2,53 \\
& Meses & $0,001011^{* *}$ & \\
\hline \multirow{2}{*}{ Condutividade elétrica } & Ambiente x Meses & $0,000474^{\mathrm{NS}}$ & 5,03 \\
& Ambiente & $4,143821^{\mathrm{NS}}$ & 4,48 \\
\hline \multirow{2}{*}{ Porcentagem de germinação } & Meses & $9,975532^{* *}$ & \\
& Ambiente x Meses & $1,412302^{* *}$ & 9,40 \\
& Ambiente & $340,333333^{*}$ & 8,30 \\
\hline \multirow{2}{*}{ IVG } & Meses & $259,052910^{* *}$ & \\
& Ambiente x Meses & $76,148148^{*}$ & 4,57 \\
\hline \multirow{2}{*}{ Signiente } & $2,682540^{* *}$ & 10,55 \\
\hline
\end{tabular}

${ }^{* *}$ Significativo a $1 \%$ pelo teste $\mathrm{F}$.

*Significativo a $5 \%$ pelo teste $\mathrm{F}$.

NS Não significativo.

Fonte: Elaboração dos autores. 
$\mathrm{Na}$ Tabela 2 estão apresentados os valores médios dos teores de água das sementes de pinhão manso armazenadas em diferentes ambientes por um período de 12 meses. Observa-se que durante o armazenamento não houve diferença no teor de água das sementes armazenadas em câmara climatizada, devido a temperatura e umidade relativa serem moderadamente mais baixas nesta condição (Figuras 1 e 2), fazendo com que as sementes entrassem em equilíbrio com as condições do ambiente em questão. Comportamento semelhante ao observado por Catunda et al. (2003), armazenando sementes de maracujá amarelo em três condições distintas durante 10 meses.

As sementes armazenadas em ambiente natural e câmara refrigerada apresentaram variações nos valores de teor de água ao longo do armazenamento. De acordo com Carvalho e Nakagawa (2000), mudanças na temperatura e umidade relativa do ar provocam constantes ajustes no teor de água das sementes armazenadas em embalagens permeáveis ao vapor de água.

Tabela 2. Teor de água das sementes de pinhão manso (\% b.u.) submetidas ao armazenamento em ambiente natural, câmara refrigerada e câmara climatizada durante 12 meses $^{1}$.

\begin{tabular}{clllllll}
\hline \multirow{2}{*}{ Ambientes } & \multicolumn{7}{c}{ Tempo de Armazenamento (meses) } \\
\cline { 2 - 7 } & \multicolumn{1}{c}{0} & 2 & 4 & \multicolumn{1}{c}{6} & \multicolumn{1}{c}{8} & 10 & 12 \\
\hline Amb. Natural & $6,81 \mathrm{aABC}$ & $6,97 \mathrm{bABC}$ & $7,52 \mathrm{abAB}$ & $7,39 \mathrm{aAB}$ & $7,55 \mathrm{aA}$ & $6,28 \mathrm{bC}$ & $6,71 \mathrm{bBC}$ \\
Câm. Refrigerada & $6,81 \mathrm{aC}$ & $8,37 \mathrm{aA}$ & $8,33 \mathrm{aA}$ & $6,96 \mathrm{abC}$ & $7,11 \mathrm{abBC}$ & $7,79 \mathrm{aAB}$ & $8,10 \mathrm{aA}$ \\
Câm. Climatizada & $6,81 \mathrm{aA}$ & $6,66 \mathrm{bA}$ & $6,72 \mathrm{bA}$ & $6,44 \mathrm{bA}$ & $6,59 \mathrm{bA}$ & $6,53 \mathrm{bA}$ & $6,48 \mathrm{bA}$ \\
\hline
\end{tabular}

1/As médias seguidas de letra minúscula na coluna e maiúscula na linha não diferem entre si pelo teste de Tukey ao nível de 5\% de significância.

Fonte: Elaboração dos autores.

Verifica-se, ainda, que com exceção do período inicial de armazenamento, houve diferença de teor de água das sementes de pinhão manso para todos os ambientes nos diferentes períodos de armazenamento das sementes. Em função da diferença de temperatura e umidade relativa entre esses ambientes e a troca constante de massa entre a semente e o ar circunvizinho. A evolução do teor de água apresentada pelas sementes armazenadas nas diferentes condições pode ser explicada pelas alterações da umidade relativa dos ambientes ao longo do armazenamento. De acordo com Bragantini (2005) os produtos tendem a ceder ou absorver a água para o ambiente que o envolve até atingir o equilíbrio, quando a umidade relativa do ambiente de armazenamento é modificada.

Na Tabela 3 encontram-se os valores médios da variável absorção de água para as sementes de pinhão manso submetidas ao armazenamento em três condições distintas de ambientes durante 12 meses. Verifica-se que as sementes armazenadas em ambiente natural apresentaram o maior valor de absorção de água, devido às características higroscópicas das sementes de pinhão manso e a maior variação da temperatura e umidade relativa neste ambiente, promovendo constantes trocas de água que podem ocasionar danos na estrutura das sementes. Segundo Ullmann et al. (2010) e Resende et al. (2008), o teste de absorção de água é um bom parâmetro para análise da danificação mecânica ocorrida, pelo fato de seus valores estarem ligados aos danos causados no tegumento e na estrutura dos grãos.

O comprometimento estrutural nas sementes de pinhão manso pode ser observado na Tabela 4 , uma vez que os maiores valores médios de condutividade 
elétrica são encontrados nas sementes armazenadas em condição de ambiente natural.

Analisando a absorção de água das sementes de pinhão manso ao longo do tempo de armazenamento em todos os ambientes, nota-se que aos dez meses de armazenamento, as sementes apresentaram o maior valor médio de absorção de água. Este comportamento foi influenciado, principalmente, pelas sementes armazenadas em ambiente natural que nesse mesmo período se encontravam com baixo teor de água (Tabela 2), fazendo com que a capacidade de absorção de água das sementes ocorresse com mais facilidade.

Tabela 3. Absorção das sementes de pinhão manso (decimal b.s) armazenadas em ambiente natural, câmara refrigerada e câmara climatizada por um período de um $\mathrm{ano}^{\underline{1}}$.

\begin{tabular}{ccccccccc}
\hline \multirow{2}{*}{ Ambientes } & \multicolumn{7}{c}{ Tempo de Armazenamento (meses) } & \multirow{2}{*}{ Média } \\
\cline { 2 - 8 } & 0 & 2 & 4 & 6 & 8 & 10 & 12 & \\
\hline Amb. Natural & 0,64 & 0,68 & 0,66 & 0,66 & 0,67 & 0,69 & 0,65 & $0,66 \mathrm{~b}$ \\
Câm. Refrigerada & 0,64 & 0,64 & 0,67 & 0,65 & 0,64 & 0,67 & 0,63 & $0,65 \mathrm{a}$ \\
Câm. Climatizada & 0,64 & 0,66 & 0,66 & 0,66 & 0,64 & 0,64 & 0,64 & $0,65 \mathrm{a}$ \\
\hline Média & $0,64 \mathrm{~A}$ & $0,66 \mathrm{AB}$ & $0,66 \mathrm{AB}$ & $0,66 \mathrm{AB}$ & $0,65 \mathrm{AB}$ & $0,66 \mathrm{~B}$ & $0,64 \mathrm{AB}$ & \\
\hline
\end{tabular}

${ }^{1 /}$ As médias seguidas de letra minúscula na coluna e maiúscula na linha não diferem entre si pelo teste de Tukey ao nível de $5 \%$ de significância.

Fonte: Elaboração dos autores.

Na Tabela 4 estão apresentados os valores médios de condutividade elétrica das sementes de pinhão manso armazenadas por 12 meses em diferentes condições de ambiente de armazenamento. Nota-se que para os três ambientes analisados, os valores de condutividade elétrica aumentaram com o tempo de armazenamento, apresentando os maiores valores nos quatro últimos meses de avaliações.

O teste de condutividade elétrica pode identificar alterações fisiológicas e bioquímicas é está relacionada com alteração ou perda de integridade das membranas celulares (DELOUCHE; BASKIN, 1973). Indicando que independentemente do ambiente de armazenamento os processos bioquímicos da semente continuam ativos, o que faz com que a lixiviação de exsudatos continue aumentando ao longo do tempo. No entanto, o armazenamento em ambientes com temperaturas mais baixas reduz o metabolismo das sementes, embora esse processo ainda esteja presente.
Verifica-se ainda que, as sementes armazenadas no ambiente natural em relação as armazenadas em câmara refrigerada e câmara climatizada, apresentaram maiores valores de condutividade elétrica em todos os meses de avaliações e que a lixiviação eletrolítica é crescente ao longo do tempo, mostrando que há um dano progressivo nas membranas celulares das sementes de pinhão manso. Resultados semelhantes foram encontrados por Freitas et. al. (2000), ao trabalharem com sementes de algodão armazenadas sob condição de ambiente não controlado.

Na Tabela 5 estão apresentados os valores médios em porcentagem de germinação das sementes de pinhão manso armazenadas por 12 meses em três ambientes distintos. Verifica-se que para todos os ambientes, o potencial germinativo das sementes diminui ao final do armazenamento. Martins, Lago e Andrade (2009), observaram comportamento similar, ao armazenar sementes de ipê branco em três condições de temperatura durante um ano. 
Tabela 4. Condutividade elétrica das sementes de pinhão manso $\left(\mu \mathrm{S} \cdot \mathrm{cm}^{-1} \cdot \mathrm{g}^{-1}\right)$ submetidas ao armazenamento em ambiente natural, câmara refrigerada e câmara climatizada durante 12 meses $^{1 /}$.

\begin{tabular}{cccccccl}
\hline \multirow{2}{*}{ Ambientes } & \multicolumn{7}{c}{ Tempo de Armazenamento (meses) } \\
\cline { 2 - 7 } & \multicolumn{1}{c}{0} & \multicolumn{1}{c}{4} & \multicolumn{1}{c}{6} & \multicolumn{1}{c}{8} & \multicolumn{1}{c}{10} & 12 \\
\hline Amb. Natural & $15,41 \mathrm{aA}$ & $14,64 \mathrm{aA}$ & $15,87 \mathrm{aAB}$ & $16,86 \mathrm{bBC}$ & $16,87 \mathrm{aBC}$ & $17,76 \mathrm{bCD}$ & $18,72 \mathrm{bD}$ \\
Câm. Refrigerada & $15,41 \mathrm{aAB}$ & $14,63 \mathrm{aA}$ & $14,76 \mathrm{aA}$ & $15,55 \mathrm{aAB}$ & $16,79 \mathrm{aBC}$ & $17,74 \mathrm{bD}$ & $15,98 \mathrm{aABC}$ \\
Câm. Climatizada & $15,41 \mathrm{aAB}$ & $14,59 \mathrm{aA}$ & $15,12 \mathrm{aAB}$ & $15,19 \mathrm{abAB}$ & $17,60 \mathrm{aC}$ & $16,18 \mathrm{aABC}$ & $16,53 \mathrm{aBC}$ \\
\hline
\end{tabular}

${ }^{1}$ As médias seguidas de letra minúscula na coluna e maiúscula na linha não diferem entre si pelo teste de Tukey ao nível de 5\% de significância.

Fonte: Elaboração dos autores.

Tabela 5. Germinação das sementes de pinhão manso (\%) armazenadas em ambiente natural, câmara refrigerada e câmara climatizada por um período de um ano ${ }^{1 /}$.

\begin{tabular}{cllllllc}
\hline \multirow{2}{*}{ Ambientes } & \multicolumn{6}{c}{ Tempo de Armazenamento (meses) } \\
\cline { 2 - 7 } & \multicolumn{1}{c}{0} & \multicolumn{1}{c}{2} & \multicolumn{1}{c}{6} & 8 & 10 & 12 \\
\hline Amb. Natural & $80,0 \mathrm{aA}$ & $66,0 \mathrm{aABC}$ & $68,33 \mathrm{aABC}$ & $72,0 \mathrm{aAB}$ & $64,0 \mathrm{aBC}$ & $59,3333 \mathrm{bBC}$ & $56,66 \mathrm{bC}$ \\
Câm. Refrigerada & $80,0 \mathrm{aA}$ & $61,33 \mathrm{aB}$ & $71,0 \mathrm{aAB}$ & $81,33 \mathrm{aA}$ & $75,33 \mathrm{aAB}$ & $75,0 \mathrm{aAB}$ & $74,0 \mathrm{aAB}$ \\
Câm. Climatizada & $80,0 \mathrm{aA}$ & $67,33 \mathrm{aAB}$ & $72,66 \mathrm{aAB}$ & $78,0 \mathrm{aAB}$ & $64,33 \mathrm{aB}$ & $73,33 \mathrm{aAB}$ & $76,0 \mathrm{aAB}$ \\
\hline
\end{tabular}

${ }^{1}$ As médias seguidas de letra minúscula na coluna e maiúscula na linha não diferem entre si pelo teste de Tukey ao nível de $5 \%$ de significância.

Fonte: Elaboração dos autores.

A redução da porcentagem de germinação é mais evidente nas sementes armazenadas em ambiente natural, apresentando redução de 23,3 pontos percentuais, enquanto as armazenadas em câmara refrigerada e câmara climatizada reduziram 6,0 e 4,0 pontos percentuais, respectivamente. Essa diferença é decorrente das maiores oscilações nas condições de temperatura e umidade relativa do ambiente natural promovendo maiores alterações nos processos bioquímicos das sementes. Santos e Paula (2005), mostraram que sementes de branquilo diminuem a porcentagem e o índice de velocidade de germinação quando armazenadas por cinco meses em sacos de papel. Indicando que além do ambiente do armazenamento, a redução da germinação pode estar relacionada à embalagem utilizada.

Observando a porcentagem de germinação das sementes de pinhão manso entre os ambientes de armazenamento em cada mês de avaliação, verificase que a condição de armazenagem não altera o poder germinativo das sementes, com exceção dos últimos dois meses daquelas armazenadas em ambiente natural. Logo, o potencial germinativo das sementes está relacionado com a condutividade elétrica das mesmas (Tabela 4). Ullmann et al. (2010), observaram a redução na porcentagem de germinação de sementes de pinhão manso quando houve um acréscimo na condutividade elétrica.

$\mathrm{Na}$ Tabela 6 estão apresentados os valores médios do IVG das sementes de pinhão manso armazenadas por 12 meses em ambiente natural, câmara refrigerada e climatizada. Verifica-se que houve uma grande variabilidade no IVG das sementes de pinhão armazenadas em câmara refrigerada e câmara climatizada e que o sexto mês de armazenamento foi o que promoveu o menor IVG para todos os ambientes. 
Tabela 6. Índice de velocidade de germinação das sementes de pinhão manso submetidas ao armazenamento em diferentes condições durante 12 meses $^{1}{ }^{1}$.

\begin{tabular}{cllccccl}
\hline \multirow{2}{*}{ Ambientes } & \multicolumn{7}{c}{ Tempo de Armazenamento (meses) } \\
\cline { 2 - 7 } & \multicolumn{1}{c}{0} & \multicolumn{1}{c}{2} & \multicolumn{1}{c}{6} & \multicolumn{1}{c}{8} & 10 & \multicolumn{1}{c}{12} \\
\hline Amb. Natural & $6,18 \mathrm{aA}$ & $6,70 \mathrm{aA}$ & $7,07 \mathrm{aA}$ & $3,84 \mathrm{aB}$ & $6,82 \mathrm{bA}$ & $6,48 \mathrm{bA}$ & $5,57 \mathrm{bA}$ \\
Câm. Refrigerada & $6,18 \mathrm{aCD}$ & $5,12 \mathrm{bDE}$ & $7,44 \mathrm{aABC}$ & $4,29 \mathrm{aE}$ & $8,02 \mathrm{aAB}$ & $8,40 \mathrm{aA}$ & $6,46 \mathrm{abBCD}$ \\
Câm. Climatizada & $6,18 \mathrm{aB}$ & $6,90 \mathrm{aB}$ & $7,72 \mathrm{aAB}$ & $3,81 \mathrm{aC}$ & $7,11 \mathrm{abAB}$ & $8,49 \mathrm{aA}$ & $7,41 \mathrm{aAB}$ \\
\hline
\end{tabular}

${ }^{1}$ As médias seguidas de letra minúscula na coluna e maiúscula na linha não diferem entre si pelo teste de Tukey ao nível de $5 \%$ de significância.

Fonte: Elaboração dos autores.

Pela análise do IVG das sementes de pinhão manso entre os diferentes ambientes de armazenamento em cada mês de avaliação, nota-se menores valores aos 8, 10 e 12 meses de armazenamento no ambiente natural e no segundo mês em câmara refrigerada. Houve uma correlação entre o IVG e a porcentagem de germinação (Tabela 5), uma vez que nesses meses as sementes armazenadas nos respectivos ambientes também apresentaram os menores valores para porcentagem de germinação. Souza et al. (2007), observaram redução na porcentagem e no índice de velocidade de germinação em sementes de camomila armazenadas por quatro anos, embora que no segundo ano os valores de germinação e IVG tenham sido maiores, mas os pesquisadores destacam que neste caso houve superação de dormência das sementes. Segundo Guimarães, Souza e Pinho (2004), sementes de erva-de-touro reduzem o IVG quando armazenadas em armazém convencional, sem o controle da temperatura e umidade relativa, e que o comportamento é inverso quando armazenadas em câmara fria e congelador por um período de dois anos.

\section{Conclusão}

As condições de temperatura e umidade relativa do ar comprometem a estrutura das sementes de pinhão manso ao longo do tempo, principalmente em ambiente natural;

A qualidade fisiológica das sementes de pinhão manso é comprometida a partir do sexto mês de armazenamento;
Os ambientes refrigerados e climatizados reduzem com menor intensidade a qualidade fisiológica e tecnológica das sementes de pinhão manso durante o armazenamento.

\section{Agradecimentos}

Ao $\mathrm{CNPq}$ e CAPES pelo apoio financeiro indispensável a execução do presente trabalho.

\section{Referências}

ABDAlLA, A. L.; SILVA FILHO, J. C.; GODOI, A. R.; CARMO, C. A.; EDUARDO, J. L. P. Utilização de subprodutos da indústria de biodiesel na alimentação de ruminantes. Revista Brasileira de Zootecnia, Viçosa, v. 37, p. 260-258, 2008. Especial.

ABDUL-BAKI, A. A.; ANDERSON, J. D. Physilogical and biochemical deterioration of seeds. In: KOSLOWSKI, T. T. (Ed.). Seed biology. New York: Academic Press, 1972. v. 2, p. 283-315.

ABU-GHANNAM, N.; MCKENNA, B. The applicationof Peleg s equation to model water absorption during the soaking of red kidney beans (Phaseolus vulgaris L.). Journal of Food Engineering, Essex, v. 32, n. 4, p. 391-401, 1997.

AFONSO JÚNIOR, P. C.; CORRÊA, P. C.; ANDRADE, E. T. Efeito do impacto mecânico induzido sobre a integridade dos grãos e a qualidade do café. Revista Brasileira de Armazenamento, Viçosa, n. 6, p. 10-18, 2003. Especial Café.

ANDRADE, E. T.; CORRÊA, P. C.; MARTINS, J. H.; ALVARENGA, E. M. Avaliação de dano mecânico em sementes de feijão por meio de condutividade elétrica. Revista Brasileira de Engenharia Agrícola e Ambiental, Campina Grande, v. 3, n. 1, p. 54-60, 1999. 
BEWLEY, J. D.; BLACK, M. Seeds: physiology of development and germination. $2^{\text {nd }}$ ed. New York: Plenum Press, 1994. 445 p.

BRAGANTINI, C. Alguns aspectos do armazenamento de sementes e grãos de feijão. Santo Antônio de Goiás. Embrapa Arroz e Feijão. 2005. 28 p.

BRASIL, Ministério da Agricultura e Reforma Agrária. Secretaria Nacional de defesa Agropecuária. Regras para análise de sementes. Brasília, 2009. 395 p.

BROOKER, D. B.; BAKKER-ARKEMA, F. W.; HALL, C. W. Drying and storage of grains and oilseeds. Westport: The AVI Publishing Company, 1992. 450 p.

CARVALHO, N. M.; NAKAGAWA, J. Sementes: ciência, tecnologia e produção. 4. ed. Jaboticabal: FUNEP, 2000. $588 \mathrm{p}$.

CATUNDA, P. H. A.; VIEIRA, H. D.; SILVA, R. F.; POSSE, S. C. P. Influência do teor de água, da embalagem e das condições de armazenamento na qualidade de sementes de maracujá amarelo. Revista Brasileira de Sementes, Londrina, v. 25, n. 1, p. 65-71, 2003.

DELOUCHE, J. C.; BASKIN, C. C. Accelerated ageing techniques for predicting the relative storability of seed lots. Seed Science and Technology, Zürich, v. 1, n. 3, p. 427-452, 1973.

FREITAS, R. A.; DIAS, D. C. F. dos S.; CECON, P. P.; REIS, S. R. Qualidade fisiológica e sanitária de sementes de algodão durante o armazenamento. Revista Brasileira de Sementes, Londrina, v. 22, n. 2, p. 94-101, 2000.

GONELI, A. L. D.; CORREA, P. C.; RESENDE, O.; REIS NETO, S. A. Estudo da difusão de umidade em grãos de trigo durante a secagem. Ciência e Tecnologia de Alimentos, Campinas, v. 27, n. 1, p. 135-140, 2007.

GUIMARÃES, S. C.; SOUZA, I. F.; PINHO, E .V. R. V. Viabilidade de sementes de erva-de-touro, sob diferentes condições de armazenamento. Planta Daninha, Londrina, v. 22, n. 2, p. 231-238, 2004.

MARTINS, L.; LAGO, A. A.; ANDRADE, A. C. S. Armazenamento de sementes de ipê-branco: teor de água e temperatura do ambiente. Bragantia, Campinas, v. 68, n. 3, p. 775-780, 2009.

NAKAGAWA, J. Testes de vigor baseados na avaliação das plântulas. In: VIEIRA, R. D.; CARVALHO, N. M. (Ed.). Testes de vigor em sementes. Jaboticabal: FUNEP, 1994. p. 44-85.

RESENDE, O.; CORREAA, P. C.; FARONI, L. R. A.; CECON, P. R. Avaliação da qualidade tecnológica do feijão durante o armazenamento. Revista Ciência e Agrotecnologia, Lavras, v. 32, n. 2, p. 517-524, 2008.
RESIO, A. N. C.; AGUERRE, R. J.; SUAREZ, C. Analysis of simultaneous water absorption and waterstarch reaction during soaking of amaranth grain. Journal of Food Engineering, Londres, v. 68, n. 2, p. 265-270, 2005.

SANTOS, S. B.; MARTINS, M. A.; CARVALHO, F. M.; CARNEIRO, A. C. O. Determinação de algumas propriedades físicas dos grãos de pinhão manso (Jatropha curcas L.) In: DI LEO, N.; MONTICO, S.; NARDÓN, G. Avances en Ingeniería rural: 2007-2009. Rosario: UNR, 2009, p. 1067-1072.

SANTOS, S. R. G.; PAULA, R. C. Teste de condutividade elétrica para avaliação da qualidade fisiológica de sementes de sebastiania commersoniana (bail) smith e downs - euphorbiaceae. Revista Brasileira de Sementes, Londrina, v. 27, n. 2, p. 136-145, 2005.

SATURNINO, H. M.; PACHECO, D. D.; KAKIDA, J.; TOMINAGA, N.; GONÇALVES, N. P. Produção de oleaginosas para o biodiesel. Informe Agropecuário, Belo Horizonte, v. 26, n. 229, p. 44-74. 2005.

SILVA, J. S. Secagem e armazenagem de produtos agrícolas. Viçosa: Aprenda Fácil, 2008. 559 p.

SOUZA, A. D. V.; FÁVARO, S. P.; ÍTAVO, L. C. V.; ROSCOE, R. Caracterização química de sementes e tortas de pinhão manso, nabo forrageiro e crambe. Pesquisa Agropecuária Brasileira, Brasília, v. 44, n. 10, p. 1328-1335, 2009.

SOUZA, J. R. P.; TAKAHASHI, L. S. A.; YOSHIDA, A. E.; GUIRAUD, M. C.; ROCH, J. N. Tempo de armazenamento e temperatura na porcentagem e velocidade de germinação das sementes de camomila. Ciência Rural, Santa Maria, v. 37, n. 4, p. 982-986, 2007.

ULLMANN, R.; RESENDE, O.; SALES, J. F.; CHAVES, T. H. Qualidade das sementes de pinhão manso submetidas à secagem artificial. Revista Ciência Agronômica, Fortaleza, v. 41, n. 3, p. 442-447, 2010.

VIEIRA, R. D.; KRZYZANOWSKI, F. C. Teste de condutividade elétrica. In: KRZYZANOWSKI, F. C.; VIEIRA, R. D.; FRANÇA NETO, J. B. (Ed.). Vigor de sementes: conceitos e testes. Londrina: ABRATES, 1999. cap. 4, p. 1-26.

VIEIRA, R. D.; PENARIOL, A. L.; PERECIN, D.; PANOBIANCO, M. Condutividade elétrica e teor de água inicial das sementes de soja. Pesquisa Agropecuária Brasileira, Brasília, v. 37, n. 9, p. 1333-1338, 2002. 